\title{
Acute renal failure: definitions, diagnosis, pathogenesis, and therapy
}

\author{
Robert W. Schrier, Wei Wang, Brian Poole, and Amit Mitra
}

Department of Medicine, University of Colorado Health Sciences Center, Denver, Colorado, USA.

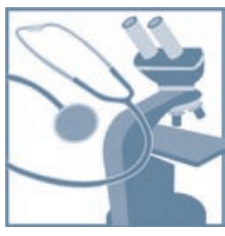

\begin{abstract}
Acute renal failure (ARF), characterized by sudden loss of the ability of the kidneys to excrete wastes, concentrate urine, conserve electrolytes, and maintain fluid balance, is a frequent clinical problem, particularly in the intensive care unit, where it is associated with a mortality of between $50 \%$ and $80 \%$. In this review, the epidemiology and pathophysiology of ARF are discussed, including the vascular, tubular, and inflammatory perturbations. The clinical evaluation of ARF and implications for potential future therapies to decrease the high mortality are described.
\end{abstract}

During the bombing of London in World War II, Bywaters and Beall described an acute loss of kidney function that occurred in severely injured crush victims (1). Acute tubular necrosis (ATN) was the term coined to describe this clinical entity, because of histological evidence for patchy necrosis of renal tubules at autopsy. In the clinical setting, the terms ATN and acute renal failure (ARF) are frequently used interchangeably. However, for the purposes of this review, the term ARF, rather than ATN, will be used. ARF will not include increases in blood urea due to reversible renal vasoconstriction (prerenal azotemia) or urinary tract obstruction (postrenal azotemia).

The mortality of ARF approached $100 \%$ in World War II, since the development of acute hemodialysis for clinical use had not yet occurred. Acute hemodialysis was first used clinically during the Korean War in 1950 to treat military casualties, and this led to a decrease in mortality of the ARF clinical syndrome from about $90 \%$ to about $50 \%(2,3)$. In the half century that has since passed, much has been learned about the pathogenesis of ischemic and nephrotoxic ARF in experimental models, but there has been very little improvement in mortality. This may be explained by changing demographics: the age of patients with ARF continues to rise, and comorbid diseases are increasingly common in this population. Both factors may obscure any increased survival related to improved critical care.

Examining the incidence of ARF in several military conflicts does, however, provide some optimism (4). The incidence of ARF in seriously injured casualties decreased between World War II and the Korean War, and again between that war and the Vietnam War, despite the lack of any obvious difference in the severity of the injuries. What was different was the rapidity of the fluid resuscitation of the patients. Fluid resuscitation on the battlefield with the rapid evacuation of the casualties to hospitals by helicopter began during the Korean War and was optimized further during the Vietnam War. For seriously injured casualties the incidence of

Nonstandard abbreviations used: acute renal failure (ARF); acute tubular necrosis (ATN); blood urea nitrogen (BUN); continuous renal replacement therapy (CRRT); fractional excretion of filtered sodium $\left(\mathrm{FE}_{\mathrm{Na}}\right)$; glomerular filtration rate (GFR); intermittent hemodialysis (IHD); lactic dehydrogenase (LDH); $\alpha$-melanocyte-stimulating hormone ( $\alpha \mathrm{MSH})$; NO synthase (NOS); Tamm-Horsfall protein (THP).

Conflict of interest: The authors have declared that no conflict of interest exists.

Citation for this article: $J$. Clin. Invest. 114:5-14 (2004).

doi:10.1172/JCI200422353.

The Science in medicine series is supported in part by a generous grant from the Doris Duke Charitable Foundation. ischemic ARF was one in 200 in the Korean War and one in 600 in the Vietnam War (5). This historical sequence of events suggests that early intervention could prevent the occurrence of ARF, at least in military casualties. In experimental studies it has been shown that progression from an azotemic state associated with renal vasoconstriction and intact tubular function (prerenal azotemia) to established ARF with tubular dysfunction occurs if the renal ischemia is prolonged (6). Moreover, early intervention with fluid resuscitation was shown to prevent the progression from prerenal azotemia to established ARF.

\section{Diagnostic evaluation of ARF}

One important question, therefore, is how to assure that an early diagnosis of acute renal vasoconstriction can be made prior to the occurrence of tubular dysfunction, thus providing the potential to prevent progression to established ARF. In this regard, past diagnostics relied on observation of the patient response to a fluid challenge: decreasing levels of blood urea nitrogen (BUN) indicated the presence of reversible vasoconstriction, while uncontrolled accumulation of nitrogenous waste products, i.e., BUN and serum creatinine, indicated established ARF. This approach, however, frequently led to massive fluid overload in the ARF patient with resultant pulmonary congestion, hypoxia, and premature need for mechanical ventilatory support and/or hemodialysis. On this background the focus turned to an evaluation of urine sediment and urine chemistries to differentiate between renal vasoconstriction with intact tubular function and established ARF (7). It was well established that if tubular function was intact, renal vasoconstriction was associated with enhanced tubular sodium reabsorption. Specifically, the fraction of filtered sodium that is rapidly reabsorbed by normal tubules of the vasoconstricted kidney is greater than $99 \%$. Thus, when nitrogenous wastes, such as creatinine and urea, accumulate in the blood due to a fall in glomerular filtration rate (GFR) secondary to renal vasoconstriction with intact tubular function, the fractional excretion of filtered sodium $\left(\mathrm{FE}_{\mathrm{Na}}=[\right.$ (urine sodium $\times$ plasma creatinine $) /$ (plasma sodium $\times$ urine creatinine)]) is less than $1 \%$. An exception to this physiological response of the normal kidney to vasoconstriction is when the patient is receiving a diuretic, including mannitol, or has glucosuria, which decreases tubular sodium reabsorption and increases $\mathrm{FE}_{\mathrm{Na}}$. It has recently been shown in the presence of diuretics that a rate of fractional excretion of urea ( $\left.\mathrm{FE}_{\text {urea }}\right)$ of less than 35 indicates intact tubular function, thus favoring renal vasoconstriction rather than established ARF as a cause of the azotemia (8). Also, renal 
vasoconstriction in a patient with advanced chronic renal failure may not be expected to be associated with an $\mathrm{FE}_{\mathrm{Na}}$ of less than 1 because of chronic adaptation to an increased single-nephron GFR. Specifically, the adaptive decrease in tubular reabsorption to maintain sodium balance in chronic renal disease may make the interpretation of $\mathrm{FE}_{\mathrm{Na}}$ difficult in this setting.

The approximately $80 \%$ diagnostic specificity of $\mathrm{FE}_{\mathrm{Na}}$ in distinguishing azotemia associated with renal vasoconstriction and intact tubular function from established ARF with tubular dysfunction may result from limited sensitivity of this parameter, or, perhaps more likely, the patient may actually be progressing from a prerenal azotemic state to established ARF. With established ARF the urine-concentrating capacity is abolished; thus measurement of urinary osmolality may complement the use of $\mathrm{FE}_{\mathrm{Na}}$ in the diagnostic separation of renal vasoconstriction from established ARF in the patient with a rising BUN measurement and serum creatinine level. Since advanced age and low protein intake may diminish maximal urinary osmolality, this diagnostic parameter may be less sensitive than $\mathrm{FE}_{\mathrm{Na}}$ in the azotemic patient. Increased excretion of tubular epithelial cells, indicated by examination of the urinary sediment, is characteristic of established ARF but also has limitations in diagnostic value particularly in nonoliguric ARF. Table 1 shows guidelines for urinary indices whereby established ARF can be distinguished from renal vasoconstriction with intact tubular function, i.e., prerenal azotemia. It also should be pointed out that some causes of ARF, including radiocontrast media and myoglobinuria, may be associated with an $\mathrm{FE}_{\mathrm{Na}}$ of less than 1 (9). This may be related to the early presence of severe renal vasoconstriction and intact distal tubule function, which can occur in the presence of proximal tubule injury.

Recent observational results suggest that for patients with a rising BUN level and/or serum creatinine concentration, early consultation with a nephrologist can decrease the occurrence and mortality of ARF (10). The reasons for this observation are not clear but may involve early evaluation by the nephrologist of not only blood but also urinary chemistries, diminished incidence of fluid overload and need for mechanical ventilation, and perhaps earlier initiation of dialysis. On this background a search for sensitive parameters for the early diagnosis of ARF and a uniformly accepted definition of established ARF has emerged. A clinical definition of ARF has been sought that focuses on the degree of nitrogenous-waste accumulation in the blood, whether serum creatinine, BUN, or cystatin C (11), in order to make an early diagnosis. This approach, however, has important limitations. With established ARF the GFR is generally less than $10 \mathrm{ml} / \mathrm{min}$. The amount of nitrogenous accumulation in the blood depends on the duration of the time that the patient has had a GFR of less than 10 $\mathrm{ml} / \mathrm{min}$. Thus, a catabolic patient with established ARF may have a serum creatinine concentration of $1.8 \mathrm{mg} / \mathrm{dl}$ when seen within the first 24 hours of established ARF, but the same individual may have a concentration of $10 \mathrm{mg} / \mathrm{dl}$ when seen after 5 days of established ARF, even though the GFR has been less than $10 \mathrm{ml} / \mathrm{min}$ in both circumstances. Nevertheless, acceptance of a $50 \%$ acute rise in serum creatinine to a concentration above $2.0 \mathrm{mg} / \mathrm{dl}$ as the clinical definition of ARF could increase the likelihood of early intervention and bring more consistency to the patient populations recruited for future intervention trials. However, such a definition does not differentiate among rises in serum creatinine that result (a) from a renal vasoconstriction-mediated prerenal azotemic state with intact tubular function, such as that which occurs with volume depletion, and advanced cardiac or liver failure; (b) from a postrenal azotemic state due to urinary tract obstruction; or (c) from established ARF due to an acute ischemic and/or nephrotoxic insult. A sensitive approach to ruling out postrenal azotemia is to identify post-void residual bladder urine as less than $50 \mathrm{ml}$ and exclude pyelocalyceal dilatation using renal ultrasonography.

The differentiation of prerenal azotemia and established ARF, however, has proven more difficult. Several biomarkers have been proposed for the early diagnosis of ARF and are currently under study. These include increased urinary excretion of kidney injury molecule-1 (12), IL-18 (13), and tubular enzymes (14). In order for any of these or other potential future biomarkers to become practical in the early clinical diagnosis of established ARF, specificity, sensitivity, rapid availability, cost effectiveness, and advantages as compared with the inexpensive and readily available measure of $\mathrm{FE}_{\mathrm{Na}}$ must be considered.

From a clinical-diagnostic viewpoint, a potential advancement may be an agreement to use the term ARF, rather than ATN, independent of whether the acute insult was ischemic or nephrotoxic. Such an agreement, however, would also necessitate using the terms prerenal azotemia and postrenal azotemia for those potentially reversible conditions that result from renal vasoconstriction and urinary tract obstruction, respectively. Alternatively, it must be recognized that diagnosis of ARF based solely on a given rise in serum creatinine, BUN, or cystatin C levels would encompass many patients who do not have the clinical syndrome of established ARF, an entity that is not readily reversible by fluid resuscitation, cardiac or hepatic functional improvement, or relief of a urinary tract obstruction.

\section{Mechanisms of ARF}

Based on the foregoing comments, this discussion of mechanisms of ARF will not include nitrogenous-waste accumulation due to renal vasoconstriction with intact tubular function (prerenal azotemia) or urinary tract obstruction (postrenal azotemia). The mechanisms of ARF involve both vascular and tubular factors (15). An ischemic insult to the kidney will in general be the cause of the ARF discussed herein. While a decrease in renal blood flow with diminished oxygen and substrate delivery to the tubule cells is an important ischemic factor, it must be remembered that a relative increase in oxygen demand by the tubule is also a factor in renal ischemia.

\section{Table 1}

Guidelines for urinary indices whereby established ARF can be distinguished from renal vasoconstriction with intact tubular function (prerenal azotemia)

$\begin{array}{lcc}\text { Laboratory test } & \text { Prerenal azotemia } & \text { ARF } \\ \text { Urine osmolality }(\mathrm{m} 0 \mathrm{sm} / \mathrm{kg}) & >500 & <400 \\ \text { Urine sodium level }(\mathrm{mEq} / \mathrm{l}) & <20 & >40 \\ \text { Urine/plasma creatinine ratio } & >40 & <20 \\ \text { Fractional excretion of sodium (\%) } & <1 & >2 \\ \text { Fractional excretion of urea (\%) } & <35 & >35 \\ \text { Urinary sediment } & \text { Normal; } & \text { Renal tubular } \\ & \text { occasional hyaline } & \text { epithelial cells; } \\ & \text { or fine granular } & \text { granular and } \\ & \text { casts } & \text { muddy brown } \\ & & \text { casts }\end{array}$

Osm, osmole; Eq, equivalent. 


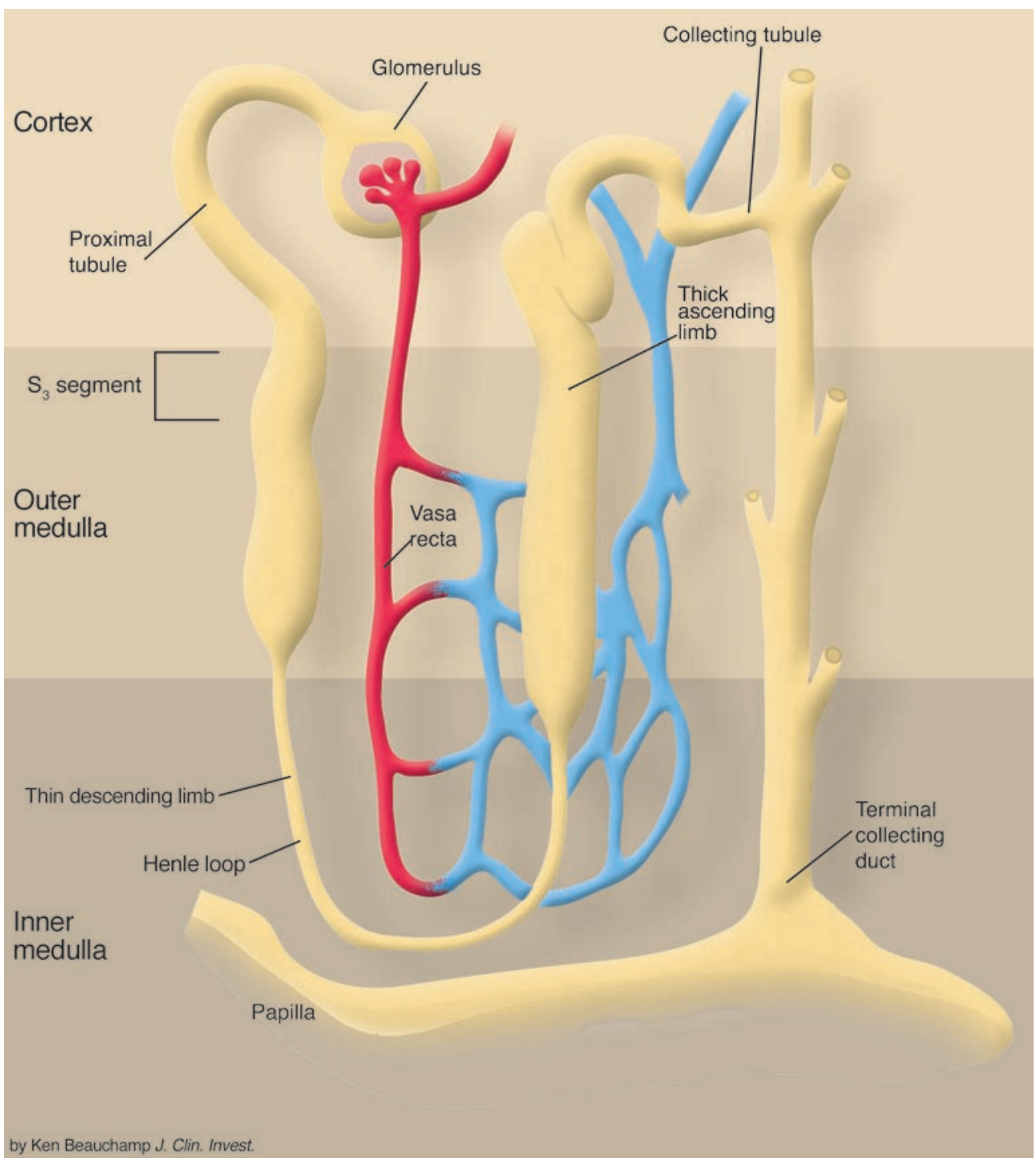

\section{Figure 1}

Relative hypoxia in the outer medulla predisposes to ischemic injury in the $S_{3}$ segment of the proximal tubule. The thick ascending limb is also located in this hypoxic region of the kidney and, depending on tubular reabsorptive demand, may also undergo ischemic injury. The thick ascending limb may, however, be more protected against ischemic injury, because this nephron segment possesses more glycolytic machinery for ATP synthesis than the $\mathrm{S}_{3}$ segment.
The term ATN, although frequently used to describe the syndrome of clinical ARF in the absence of prerenal and postrenal azotemia, is somewhat of a misnomer. Specifically, in established ARF the presence of tubular necrosis upon histological examination of the kidney is seen in only occasional tubule cells at best and, in some cases, may not even be detectable (16). What is clear with established ARF, however, is that the glomeruli are morphologically normal. This perhaps justifies the investigative focus on renal tubules. The following discussion will describe some of the vascular, tubular, and inflammatory perturbations that occur with an acute renal insult. An attempt will then be made to integrate the important underlying pathogenetic factors.

\section{Renal vascular abnormalities}

Loss of autoregulation and increased renal vasoconstriction: the role of increased cytosolic and mitochondrial calcium. Acute ischemic injury has been shown in experimental animals to be associated with a loss of renal autoregulation (17). Moreover, rather than the normal autoregulatory renal vasodilation that occurs during a decrease in renal perfusion pressure, there is evidence that renal vasoconstriction actually occurs in the ischemic kidney. An increase in the response to renal nerve stimulation has also been observed in association with an acute ischemic insult (17). Moreover, the vasoconstrictor response to exogenous norepinephrine and endothelin has been observed to be increased in the acutely ischemic kidney (18). These vascular abnormalities observed in the ischemic kidney may be related to the resultant increase in cytosolic calcium observed in the afferent arterioles of the glomerulus. The observation that intrarenal calcium channel blockers can reverse the loss of autoregulation and the increase in sensitivity to renal nerve stimulation (17) supports a pathogenetic role of increased cytosolic calcium concentration in the afferent arteriole of the ischemic kidney. The mitochondrial calcium accumulation in the ischemic kidney has also been reversed by administration of calcium channel blockers (19-21). Moreover, calcium channel blockers have been shown to attenuate renal dysfunction and toxicity associated with the immunosuppressive drug cyclosporine following cadaveric renal transplantation, when administrated prior to the drug and ischemic insults (22).

Outer medullary congestion. Outer medullary congestion of the kidney is another vascular hallmark of acute renal ischemia. This congestion has been proposed to worsen the relative hypoxia in the outer 


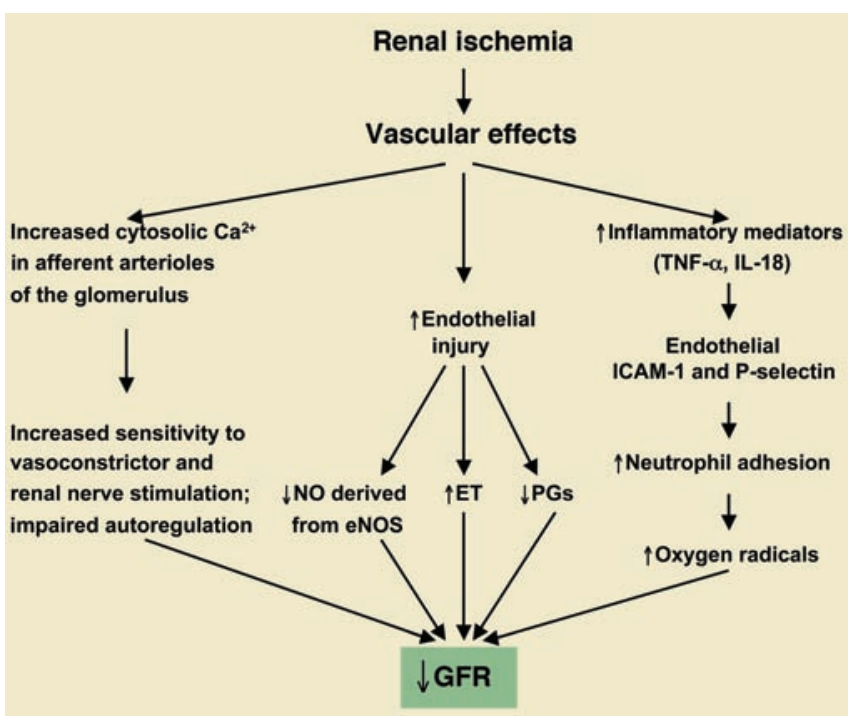

Figure 2

Vascular factors contributing to the pathogenesis of ischemic ARF. ET, endothelin; PG, prostaglandin. Figure modified with permission from the Journal of Nephrology (15).

medulla and thus the hypoxic injury in the $S_{3}$ segment of the proximal tubule and the thick ascending limb of the Henle loop (Figure 1) (23). Upregulation of adhesion molecules has been implicated in this outer medullary congestion, and antibodies to ICAMs and P-selectin have been shown to afford protection against acute ischemic injury (24-27). Acute renal ischemia has also been shown to be associated with endothelial damage, perhaps at least in part because of increased oxidant injury. Some evidence in support of this possibility is the observation that activated leukocytes enhance the renal ischemic injury, and this observation could not be duplicated using leukocytes from patients with chronic granulomatous disease that do not produce reactive oxygen species (28). Oxidant injury may also lead to a decrease in eNOS and vasodilatory prostaglandins as well as an increase in endothelin, all of which may enhance the renal vasoconstrictor effect of circulating pressor agents present in ARF (29-31).

With this spectrum of vascular consequences observed in association with an acute ischemic insult (Figure 2), an earlier suggestion was made that the term ATN should be exchanged for the term vasomotor nephropathy. However, renal vasodilators, which return renal blood flow to normal in experimental ARF animal models and humans with established ARF, have not been shown to increase GFR. Thus, in recent years the search for the mechanisms mediating ARF has focused primarily on the renal tubule.

\section{Tubular abnormalities}

There is no question that renal tubule dysfunction occurs in established ARF, since tubular sodium reabsorption is decreased, i.e., $\mathrm{FE}_{\mathrm{Na}}>2.0$, at a time when normal renal tubules avidly increase tubular sodium reabsorption in response to renal vasoconstriction. However, investigators of tubular abnormalities, which occur following acute renal ischemic insults, must ultimately demonstrate how the observed tubule perturbation mediates the fall in GFR to less than $10 \%$ of normal - the hallmark of established ARF.

Structural changes during ischemic ARF. ARF is characterized by tubular dysfunction with impaired sodium and water reabsorp- tion and is associated with the shedding and excretion of proximal tubule brush border membranes and epithelial tubule cells into the urine (32) (Figure 3). Approximately 30-70\% of these shed epithelial tubule cells in the urine are viable and can be grown in culture (33). Recent studies using cellular and molecular techniques have provided information relating to the structural abnormalities of injured renal tubules that occur both in vitro and in vivo. In vitro studies using chemical anoxia have revealed abnormalities in the proximal tubule cytoskeleton that are associated with translocation of $\mathrm{Na}^{+} / \mathrm{K}^{+}$-ATPase from the basolateral to the apical membrane (34) (Figure 3). A comparison of cadaveric transplanted kidneys with delayed versus prompt graft function has also provided important results regarding the role of $\mathrm{Na}^{+} / \mathrm{K}^{+}$-ATPase in ischemic renal injury (35). This study demonstrated that, compared with kidneys with prompt graft function, those with delayed graft function had a significantly greater cytoplasmic concentration of $\mathrm{Na}^{+}$/ $\mathrm{K}^{+}$-ATPase and actin-binding proteins - spectrin (also known as fodrin) and ankyrin - that had translocated from the basolateral membrane to the cytoplasm (Figure 4). Such a translocation of $\mathrm{Na}^{+} / \mathrm{K}^{+}$-ATPase from the basolateral membrane to the cytoplasm could explain the decrease in tubular sodium reabsorption that occurs with ARF. The mechanisms whereby the critical residence of $\mathrm{Na}^{+} / \mathrm{K}^{+}$-ATPase in the basolateral membrane, which facilitates vectorial sodium transport, is uncoupled by hypoxia or ischemia have been an important focus of research. The actin-binding proteins, spectrin and ankyrin, serve as substrates for the calcium-activated cysteine protease calpain (36) (Figure 5). In this regard, in vitro studies in proximal tubules have shown a rapid rise in cytosolic calcium concentration during acute hypoxia, which antedates the evidence of tubular injury as assessed by lactic dehydrogenase (LDH) release (37) (Figure 6).

There is further evidence to support the importance of the translocation of $\mathrm{Na}^{+} / \mathrm{K}^{+}$-ATPase from the basolateral membrane to the cytoplasm during renal ischemia/reperfusion. Specifically, calpain-mediated breakdown products of the actin-binding protein spectrin have been shown to occur with renal ischemia. Calpain activity was also demonstrated to be increased during hypoxia in isolated proximal tubules (38). Measurement of LDH release following calpain inhibition has demonstrated attenuation of hypoxic damage to proximal tubules (39). There was no evidence in proximal tubules during hypoxia of an increase in cathepsin, another cysteine protease. Further studies demonstrated a calcium-independent pathway for calpain activation during hypoxia. Calpastatin, an endogenous cellular inhibitor of calpain activation, was shown to be diminished during hypoxia in association with the rise in another cysteine protease, caspase (40). This effect of diminished calpastatin activity could be reversed by caspase inhibition. In Figure 7, proteolytic pathways that may be involved in calpain-mediated proximal tubule cell injury during hypoxia are illustrated. Calcium activation of phospholipase A has also been shown to contribute to renal tubular injury during ischemia (41).

Tubular obstruction in ischemic ARF. The existence of proteolytic pathways involving cysteine proteases, namely calpain and caspases, may therefore explain the decrease in proximal tubule sodium reabsorption and increased $\mathrm{FE}_{\mathrm{Na}}$ secondary to proteolytic uncoupling of $\mathrm{Na}^{+} / \mathrm{K}^{+}$-ATPase from its basolateral membrane anchoring proteins. This tubular perturbation alone, however, does not explain the fall in GFR that leads to nitrogenous-waste retention and thus the rise in BUN and serum creatinine. There are, however, potential pathways whereby loss of brush border membranes, loss 


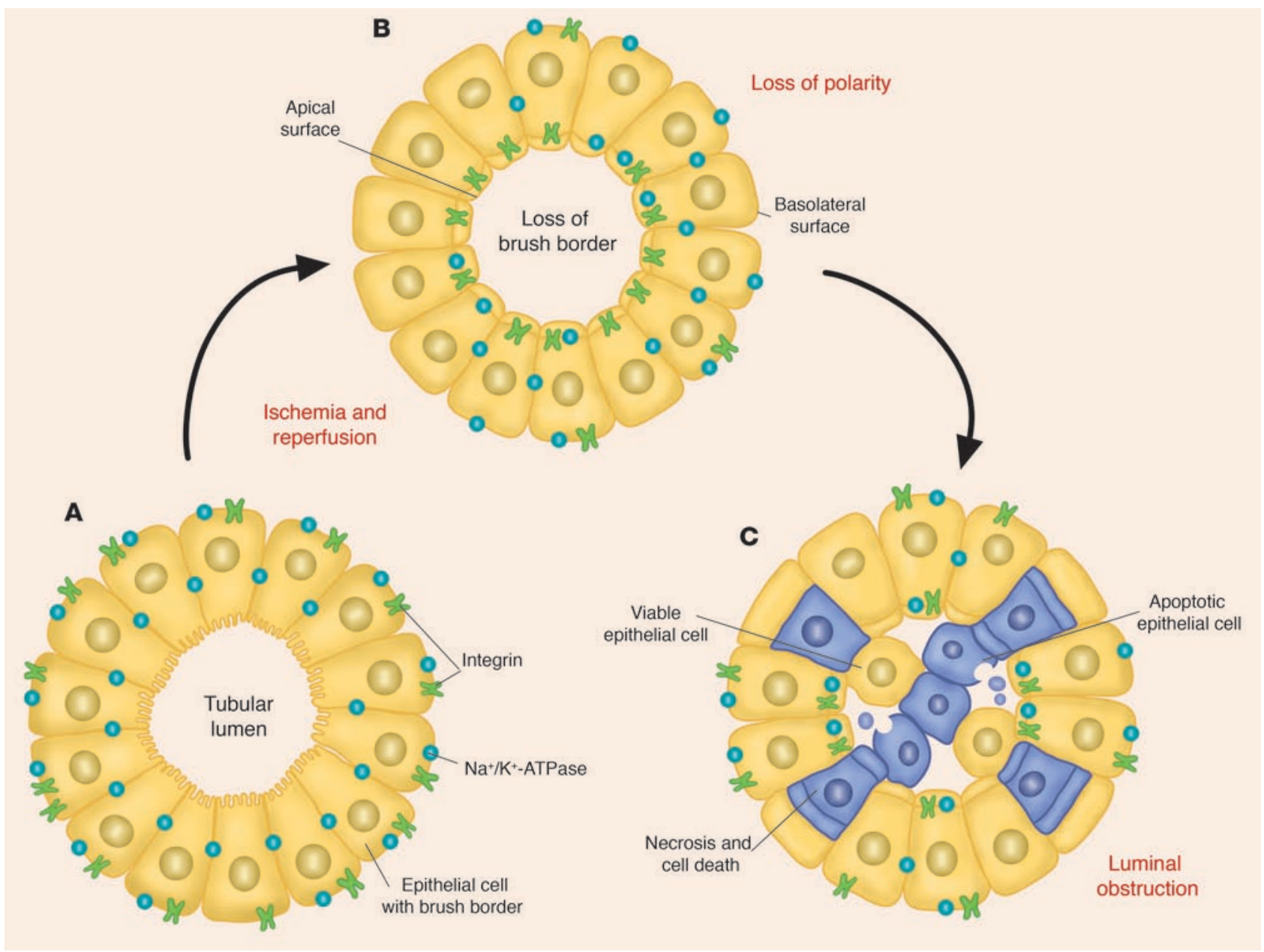

Figure 3

Following ischemia and reperfusion, morphological changes occur in the proximal tubules, including loss of polarity, loss of the brush border, and redistribution of integrins and $\mathrm{Na}^{+} / \mathrm{K}^{+}$-ATPase to the apical surface. Calcium and reactive oxygen species may also have a role in these morphological changes, in addition to subsequent cell death resulting from necrosis and apoptosis. Both viable and nonviable cells are shed into the tubular lumen, resulting in the formation of casts and luminal obstruction and contributing to the reduction in the GFR. Figure modified with permission from the New England Journal of Medicine (94).

of viable and nonviable proximal tubule cells, and decreased proximal tubule sodium reabsorption may lead to a decreased GFR during ARF. First of all, brush border membranes and cellular debris could provide the substrate for intraluminal obstruction in the highly resistant portion of distal nephrons (Figure 3). In fact, microdissection of individual nephrons of kidneys from patients with ARF demonstrated obstructing casts in distal tubules and collecting ducts (42). This observation could explain the dilated proximal tubules that are observed upon renal biopsy of ARF kidneys, even though GFR is less than $10 \%$ of normal. The intraluminal casts in ARF kidneys stain prominently for Tamm-Horsfall protein (THP), which is produced in the thick ascending limb (Figure 8). Importantly, THP is secreted into tubular fluid as a monomer but subsequently may become a polymer that forms a gel-like material in the presence of increased luminal $\mathrm{Na}^{+}$concentration, as occurs in the distal nephron during clinical ARF with the decrease in tubular sodium reabsorption (43). Thus, the THP polymeric gel in the distal nephron provides an intraluminal environment for distal cast formation involving viable, apoptotic, and necrotic tubule epithelial cells, brush border membranes, and ECM (extracellular matrix) (e.g., fibronectin) (Figure 3) (44). Whether tubular obstruction by casts is alone sufficient to account for the decreased GFR associated with clinical ARF is unknown. Certainly, net transglomerular capillary pressure can be decreased secondary to increased tubule pressure, as has been demonstrated using micropuncture techniques in experimental animals with acute ureteral obstruction (45). However, micropuncture studies in kidneys with acute ischemic injury have demonstrated that normalization of proximal tubular flow rate in a single nephron can dislodge some previously obstructing luminal casts and improve GFR in the same nephron (46). Thus, it can be proposed that at least some of the luminal casts would not cause obstruction to tubular flow if glomerular and thus tubular pressures were normal.

There is some experimental evidence that viable tubular epithelial cells released into the lumen during ischemia may adhere to other tubular cells and ECM and thereby cause intraluminal obstruction. This cellular adhesion during acute renal ischemia has been shown to involve integrin-mediated adhesion molecules via 


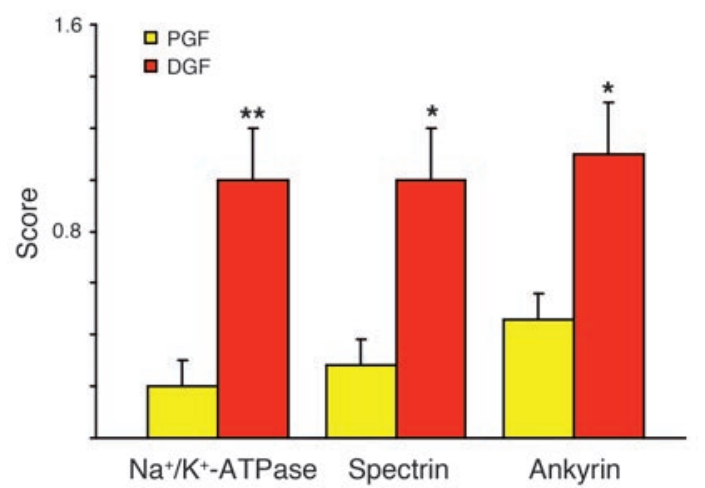

Figure 4

Immunofluorescent staining revealed the cellular location of the actinbinding proteins ankyrin, spectrin, and $\mathrm{Na}^{+} / \mathrm{K}^{+}$-ATPase in cadaveric transplanted kidneys with prompt graft function (PGF) and delayed graft function (DGF) (35). The stained sections were examined at $\times 60-600$ magnification using a scanning laser confocal microscope. Scoring was done as follows: 0 , continuous staining confined to the basolateral membrane; $0.5,1.0$, and 1.5 , interrupted linear staining of basolateral membrane with less than $50 \%$, approximately $50 \%$, and greater than $50 \%$ of the staining, respectively, appearing in the cytoplasm. In kidneys with delayed graft function, approximately $50 \%$ of the ankyrin, spectrin, and $\mathrm{Na}^{+} / \mathrm{K}^{+}$-ATPase was translocated from the basolateral membrane to the cytoplasm, whereas those kidneys with prompt graft function had only minimal translocation of these proteins from the basolateral membrane. ${ }^{\star} P<0.01$ vs. PGF, ${ }^{\star \star} P<0.05$ vs. PGF.

binding to Arg-Gly-Asp (RGD) sequences (47). In support of this possibility, synthetic cyclical RGD compounds administered during the reperfusion period have been shown to attenuate tubular obstruction and to reverse the related increase in proximal tubular pressure (48). Relief of tubular obstruction in experimental ARF, as assessed by nephron micropuncture, has also been shown with a solute diuresis induced by mannitol (49).

Tubuloglomerular balance and tubular fluid backleak in ischemic $A R F$. The decrease in proximal tubular sodium reabsorption that is associated with acute ischemic injury would increase sodium chloride delivery to the macula densa and thereby activate the tubuloglomerular feedback mechanism and decrease GFR (50). Micropuncture perfusion studies delivering increased sodium chloride to the macula densa have demonstrated a decrease in single-nephron GFR by as much as $50 \%$ (50). This degree of decline in GFR, however, could not explain the much greater decrease in GFR that is characteristic of clinical ARF. However, since the tone of the afferent arteriole modulates the tubuloglomerular feedback mechanism, the increased sensitivity of this glomerular arteriole to vasoconstriction, as discussed earlier (18), could enhance the sensitivity of the tubuloglomerular feedback response in patients with clinical ARF. Moreover, the combination of tubular cast formation and activation of the tubuloglomerular feedback mechanism during acute renal ischemia, both of which can be linked to the ARF-related decrease in proximal tubular sodium reabsorption, can provide an adequate explanation for the drastic fall in GFR observed in clinical ARF. With respect to the role of tubuloglomerular feedback in ischemic ARF, a potential beneficial effect should also be considered. Activation of the tubuloglomerular feedback mechanism and the resultant decrease in GFR during acute renal ischemia would decrease sodium chloride delivery to damaged tubules, thereby lessening the demand for ATPdependent tubular reabsorption.

The loss of the tubular epithelial cell barrier and/or the tight junctions between viable cells (51) during acute renal ischemia could lead to a leak of glomerular filtrate back into the circulation. If this occurs and normally non-reabsorbable substances, such as inulin, leak back into the circulation, then a falsely low GFR will be measured as inulin clearance. It should be noted, however, that the degree of extensive tubular damage observed in experimental studies demonstrating tubular fluid backleak is rarely observed with clinical ARF in humans (52). Moreover, dextran sieving studies in patients with ARF demonstrated that, at best, only a $10 \%$ decrease in GFR could be explained by backleak of filtrate (53). Cadaveric transplanted kidneys with delayed graft function, however, may have severe tubular necrosis, and thus backleak of glomerular filtration may be more important in this setting. The various potential mechanisms whereby alterations in tubular factors can decrease GFR in ischemic renal injury are shown in Figure 9.

\section{Inflammation}

There is now substantial evidence for the involvement of inflammation in the pathogenesis of the decreased GFR associated with acute renal ischemic injury. In this regard, there is experimental evidence that iNOS may contribute to tubular injury during ARF. Hypoxia in isolated proximal tubules has been shown to increase NO release (54), and Western blot analysis in ischemic kidney homogenates has demonstrated increased iNOS protein expression (55). An antisense oligonucleotide was shown to block the upregulation of iNOS and afford functional protection against acute renal ischemia (55). Moreover, when isolated proximal tubules from iNOS, eNOS, and neuronal NO synthase (nNOS) knockout mice were exposed to hypoxia, only the tubules from the iNOS knockout mice were protected against hypoxia, as assessed by LDH release (56). The iNOS knockout mice were also shown to have lower mortality during ischemia/reperfusion than wild-type mice (57).

There is also evidence that the scavenging of NO by oxygen radicals produces peroxynitrite that causes tubule damage during ischemia (58-60). The administration of $\alpha$-melanocyte-stimulating hormone

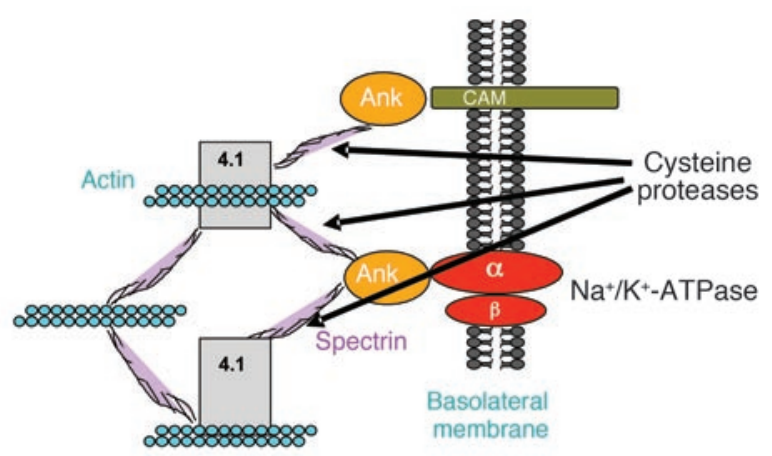

\section{Figure 5}

Potential cytoskeletal targets of cysteine proteases during hypoxia/ ischemia in proximal tubules. The basolateral membrane of the proximal tubules contains the subunits of $\mathrm{Na}^{+} / \mathrm{K}^{+}-$ATPase, which are linked to the actin cytoskeleton by ankyrin and spectrin. This forms a metabolically stable complex. Potential cytoskeletal targets of cysteine proteases during hypoxia/ischemia are shown. Ank, ankyrin; CAM, cell adhesion molecule; 4.1, protein 4.1. Figure reproduced with permission from Taylor \& Francis (36). 


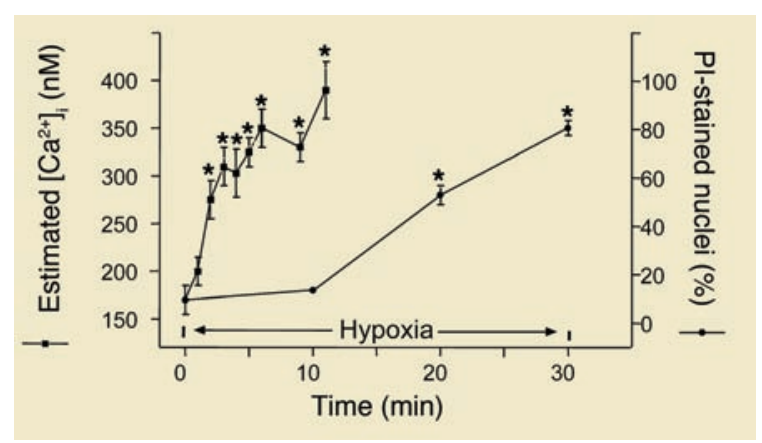

\section{Figure 6}

Increased free, intracellular $\mathrm{Ca}^{2+}$ concentration in isolated proximal tubules during hypoxia (measured with the fluorescent $\mathrm{Ca}^{2+}$ indicator Fura-2) precedes cell membrane damage, as assessed by propidium iodide (PI) staining (37). *Significant vs. time 0.

$(\alpha \mathrm{MSH})$ affords protection against ischemic/reperfusion renal injury by blocking both the induction of iNOS and leukocyte infiltration into the kidney during ischemia (61). Oxygen radical scavengers, such as superoxide dismutase, have also been shown to protect against acute renal injury associated with endotoxemia (62). Caspase inhibitors, IL-18 antibodies, and caspase- 1 knockout mice have also been shown to be protective against ischemia/reperfusion injury $(63,64)$.

While iNOS may contribute to ischemic injury of renal tubules, there is evidence that the vascular effect of eNOS in the glomerular afferent arteriole is protective against ischemic injury. In this regard, eNOS knockout mice have been shown to be more sensitive to endotoxin-related injury than normal mice (65). Moreover, the protective role of vascular eNOS may be more important than the deleterious effect of iNOS at the tubule level during renal ischemia. The basis for this tentative conclusion is the observation that treatment of mice with the nonspecific NO synthase (NOS) inhibitor L-NAME, which blocks both iNOS and eNOS, worsens renal ischemic injury as compared with vehicle treatment (66). It has also been demonstrated that NO may downregulate eNOS (67) and is a potent inducer of heme oxygenase- 1 , which has been shown to be cytoprotective against renal injury (68).

The MAPK pathway also appears to be involved in renal oxidant injury. Activation of extracellular signal-regulated kinase (ERK) or inhibition of JNK has been shown to ameliorate oxidant injury-induced necrosis in mouse renal proximal tubule cells in vitro (69). Upregulation of ERK may also be important in the effect of preconditioning whereby early ischemia affords protection against a subsequent ischemia/reperfusion insult (70).

Alterations in cell cycling have also been shown to be involved in renal ischemic injury. Upregulation of p21, which inhibits cell cycling, appears to allow cellular repair and regeneration, whereas homozygous p21 knockout mice demonstrate enhanced cell necrosis in response to an ischemic insult (71).

\section{Therapies}

Renal replacement therapy for ARF generally involves intermittent hemodialysis (IHD) or continuous renal replacement therapy (CRRT), e.g., continuous veno-veno-hemofiltration (CVVH). Since the hemodynamic stress is less with CVVH than with IHD, it is possible that any additional hemodynamic or nephrotoxic insult, which might prolong the course of ARF and thereby increase mortality, might be less with CRRT. The most recent metaanalysis, however, of randomized results comparing IHD with CRRT in ARF has not shown any difference in survival (72).

As with most disease conditions, the earlier an intervention can be instituted in acute renal ischemia, the more favorable the outcome. Thus, biomarkers more sensitive than the rise in serum creatinine concentration associated with ARF will be necessary to achieve early intervention. As previously discussed, there are several diagnostic markers under study. Presently, however, the determination of $\mathrm{FE}_{\mathrm{Na}}$ using spot urine and blood sodium and creatinine measurements is the primary and most readily available early marker of established ARF.

Prolonged duration of the ARF clinical course and the need for dialysis are major factors projecting a poor prognosis. Patients with ARF who require dialysis have a 50-70\% mortality rate. Infection and cardiopulmonary complications are the major causes of death in patients with ARF. Excessive fluid administration in patients with established ARF may lead to pulmonary congestion, hypoxia, the need for ventilatory support, pneumonia, and multiorgan dysfunction syndrome, which has an $80-90 \%$ mortality rate $(9,73,74)$. Until means to reverse the diminished host defense mechanisms in azotemic patients with clinical ARF are available, every effort should be made to avoid invasive procedures such as the placement of bladder catheters, intravenous lines, and mechanical ventilation.

Over and above such supportive care, it may be that combination therapy will be necessary to prevent or attenuate the course of ARF. Such combination therapy must involve agents with potential beneficial effects on vascular tone, tubular obstruction, and inflammation. However, vasodilator agents such as calcium channel blockers and natriuretic peptides may induce unwanted side effects such as systemic vasodilation and hypotension (75, 76), which increase sympathetic tone and activity of the reninangiotensin system (77). These compensatory neurohormonal responses support blood pressure but cause renal vasoconstric-

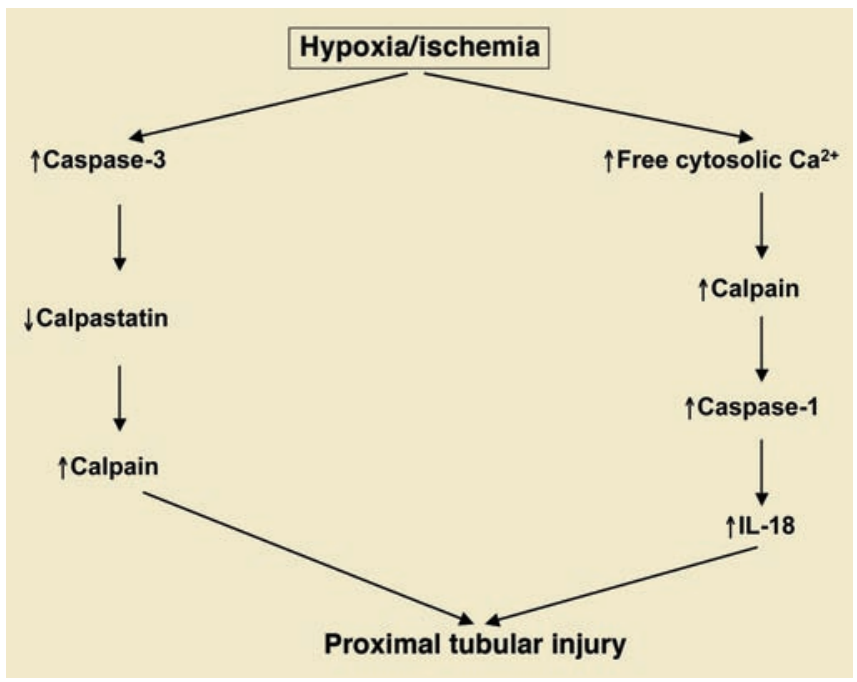

\section{Figure 7}

Hypoxic/ischemic proximal tubular necrosis results in activation of cysteine protease pathways involving calpains and both caspase-1 (an inflammatory caspase) and caspase-3 (an executioner caspase involved in apoptosis). Calpain is activated both by increased free cytosolic $\mathrm{Ca}^{2+}$ and decreased calpastatin. Calpain then activates caspase-1, which stimulates the inflammatory cytokine IL-18. The executioner caspase-3 cleaves calpastatin (40). 


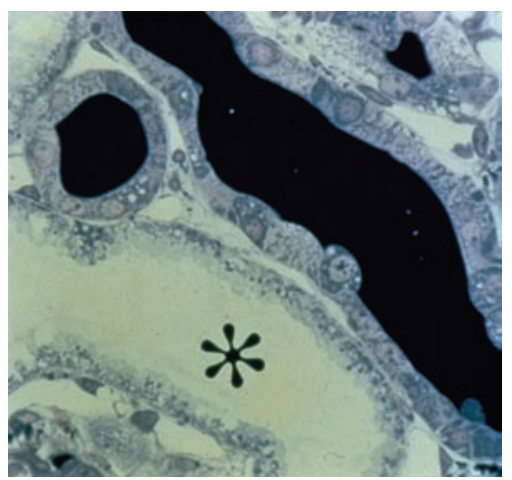

Figure 8

Staining of Tamm-Horsfall protein of casts in renal tubules and dilated tubules in ischemic ARF. The asterisk indicates the tubular lumen. $\times 100$.

tion (78), which may obscure beneficial effects of calcium channel blockers and natriuretic peptides on the kidney.

Since an improvement of GFR of only $10 \mathrm{ml} / \mathrm{min}$ from each kidney of a patient with ARF may circumvent the need for dialysis and potentially improve survival, the bilateral intrarenal infusion of a short-acting vasodilator and/or an impermeant solute such as mannitol is a potential approach that is less invasive than hemodialysis (79). Another approach is to combine a systemic vasodilator such as a natriuretic peptide, with dopamine (80) or mannitol (81), which not only will attenuate the systemic hypotensive effects of the vasodilator but can also increase tubular solute flow and thereby decrease tubular obstruction. This combined therapeutic approach has been shown to be effective in acute renal injury in experimental animals (81).

The effect of antiinflammatory agents, including reactive oxygen species scavengers, in the treatment of ARF should also be investigated. As discussed earlier, the use of inhibitors of NOS must be specific, since ARF is made more severe by nonspecific NOS inhibition (66). For example, a specific iNOS inhibitor, L-NIL, has been shown to afford protection in sepsis-related ARF in the rat (67). In this regard, cytokine-induced tubular damage may occur in sepsis in the absence of a decrease in renal blood flow. The antiinflammatory effect of and inhibition of iNOS by $\alpha \mathrm{MSH}$, which has been shown to be effective up to 8 hours after the insult, also needs to be studied as an approach to alter the course of clinical ARF (61). Inhibition of TNF- $\alpha$ has afforded renal protection in experimental endotoxemic ARF (82). However, the administration of antibodies to TNF- $\alpha$ in septic patients has not improved survival (83). In acute renal ischemia, the cellular breakdown of ATP occurs with leakage of the nucleotide products out of tubular cells. On this background, the administration of exogenous ATP has been shown to afford protection in experimental ischemic ATP. While ATP salvage has been shown to be protective against experimental tubular necrosis (84), recent experimental evi-

\section{Figure 9}

Effects of ischemia on renal tubules in the pathogenesis of ischemic ARF. cPLA2, cytosolic phospholipase A2; $\mathrm{HSP}$, heat shock protein. Figure modified with permission from the Journal of Nephrology (15). dence has suggested that GTP salvage may be preferred in preventing apoptosis associated with acute renal injury (85). The effect of the administration of synthetic RGD peptides to attenuate tubular obstruction has yet to be examined in clinical ARF. However, since patients are generally seen after clinical ARF is established with a GFR less than $10 \%$ of normal, delivery of these synthetic RGD peptides to the tubular lumen would be difficult in the absence of accompanying intrarenal vasodilation. Experiments examining upregulation of heat shock proteins $(57,86)$ or the protective effects of preconditioning against a later insult (70) suggest intriguing renal-protective approaches in need of further study.

Since patients with clinical ARF are generally seen after the insult, with the exception of kidney transplant subjects (22) and recipients of radiocontrast media (87), ways to enhance recovery and thereby lessen the duration of clinical ARF have been sought. Unfortunately, the beneficial effects of insulin-derived growth factor observed in experimental animals were not duplicated in a randomized study of patients with clinical ARF (88). A recent exciting approach in this area has been the administration of stem cells or endothelial cells to enhance recovery from acute ischemic renal injury in experimental animals (89-92). There is ongoing research into the mechanisms whereby injured tubules are relined with new cells actively engaged in DNA synthesis. The pathways by which surviving cells reenter the cell cycle and replicate may involve the early immediate response genes (93).

In summary, while much has been learned about acute renal ischemic injury, which is frequent in hospitalized patients, the mortality of clinical ARF remains high. The future, however, holds substantial promise for earlier diagnosis and effective interventions that are able to prevent or shorten the course of acute renal injury and thus improve survival. An ARF network for clinical trials with adequate statistical power would certainly facilitate this process.

\section{Acknowledgments}

This work was supported by National Institute of Diabetes and Digestive and Kidney Diseases grant DK52599.

Address correspondence to: Robert W. Schrier, Department of Medicine, University of Colorado Health Sciences Center, 4200 East Ninth Avenue, Box C-281, Denver, Colorado 80262, USA. Phone: (303) 3158059; Fax: (303) 315-2685; E-mail: robert.schrier@uchsc.edu. 
1. Bywaters, E.G., and Beall, D. 1941. Crush injuries with impairment of renal function. Br. Med. J. 1:427-432.

2. Teschan, P.E., et al. 1955. Post-traumatic renal insufficiency in military casualties. I. Clinical characteristics. Am. J. Med. 18:172-186.

3. Smith, L.H., Jr., et al. 1955. Post-traumatic renal insufficiency in military casualties. II. Management, use of an artificial kidney, prognosis. Am.J. Med. 18:187-198.

4. Butkus, D.E. 1984. Post-traumatic acute renal failure in combat casualties: a historical review. Mil. Med. 149:117-124.

5. Whelton, A., and Donadio, J.V., Jr. 1969. Post-traumatic acute renal failure in Vietnam. A comparison with the Korean war experience. Johns Hopkins Med. J. 124:95-105

6. Reineck, H.J., O'Connor, G.J., Lifschitz, M.D., and Stein, J.H. 1980. Sequential studies on the pathophysiology of glycerol-induced acute renal failure. J. Lab. Clin. Med. 96:356-362.

7. Miller, T.R., et al. 1978. Urinary diagnostic indices in acute renal failure: a prospective study. Ann. Intern. Med. 89:47-50.

8. Carvounis, C.P., Nisar, S., and Guro-Razuman, S. 2002. Significance of the fractional excretion of urea in the differential diagnosis of acute renal failure. Kidney Int. 62:2223-2229.

9. Esson, M.L., and Schrier, R.W. 2002. Diagnosis and treatment of acute tubular necrosis. Ann. Intern. Med. 137:744-752.

10. Mehta, R.L., et al. 2002. Nephrology consultation in acute renal failure: does timing matter? Am. J. Med. 113:456-461.

11. Coll, E., et al. 2000. Serum cystatin C as a new marker for noninvasive estimation of glomerular filtration rate and as a marker for early renal impairment. Am. J. Kidney Dis. 36:29-34

12. Han, W.K., Bailly, V., Abichandani, R., Thadhani, R., and Bonventre, J.V. 2002. Kidney Injury Molecule-1 (KIM-1): a novel biomarker for human renal proximal tubule injury. Kidney Int. 62:237-244.

13. Parikh, C.R., Jani, A., Melnikov, V.Y., Faubel, S., and Edelstein, C.L. 2004. Urinary interleukin-18 is a marker of human acute tubular necrosis. Am. J. Kidney Dis. 43:405-414.

14. Westhuyzen, J., et al. 2003. Measurement of tubular enzymuria facilitates early detection of acute renal impairment in the intensive care unit. Nephrol. Dial. Transplant. 18:543-551.

15. Kribben, A., Edelstein, C.L., and Schrier, R.W. 1999. Pathophysiology of acute renal failure. J. Nephrol. 12(Suppl. 2):S142-S151.

16. Racusen, L.C., and Nast, C.C. 1999. Renal histopathology, urine cytology, and cytopathology in acute renal failure. In Atlas of diseases of the kidney. R.W. Schrier, editor. Blackwell Science. Philadelphia, Pennsylvania, USA. 1-9, 12.

17. Conger, J.D., Robinette, J.B., and Schrier, R.W. 1988. Smooth muscle calcium and endothelium-derived relaxing factor in the abnormal vascular responses of acute renal failure. J. Clin. Invest. 82:532-537.

18. Conger, J.D., and Falk, S.A. 1993. Abnormal vasoreactivity of isolated arterioles from rats with ischemic acute renal (ARF) [abstract]. J. Am. Soc Nephrol. 4:733A.

19. Burke, T.J., et al. 1984. Protective effect of intrarenal calcium membrane blockers before or after renal ischemia. Functional, morphological, and mitochondrial studies. J. Clin. Invest. 74:1830-1841.

20. Arnold, P.E., Lumlertgul, D., Burke, T.J., and Schrier, R.W. 1985. In vitro versus in vivo mitochondrial calcium loading in ischemic acute renal failure. Am. J. Physiol. 248:F845-F850.

21. Arnold, P.E., Van Putten, V.J., Lumlertgul, D., Burke, T.J., and Schrier, R.W. 1986. Adenine nucleotide metabolism and mitochondrial $\mathrm{Ca} 2+$ transport following renal ischemia. Am. J. Physiol.
250:F357-F363.

22. Neumayer, H.H., and Wagner, K. 1987. Prevention of delayed graft function in cadaver kidney transplants by diltiazem: outcome of two prospective, randomized clinical trials. J. Cardiovasc. Pharmacol. 10(Suppl. 10):S170-S177.

23. Mason, J., Torhorst, J., and Welsch, J. 1984. Role of the medullary perfusion defect in the pathogenesis of ischemic renal failure. Kidney Int. 26:283-293.

24. Kelly, K.J., Williams, W.W., Jr., Colvin, R.B., and Bonventre, J.V. 1994. Antibody to intercellular adhesion molecule 1 protects the kidney against ischemic injury. Proc. Natl. Acad. Sci. U. S. A. 91:812-816.

25. Molitoris, B.A., and Marrs, J. 1999. The role of cell adhesion molecules in ischemic acute renal failure. Am. J. Med. 106:583-592.

26. Zizzi, H.C., et al. 1997. Quantification of P-selectin expression after renal ischemia and reperfusion. J. Pediatr. Surg. 32:1010-1013.

27. Singbartl, K., Green, S.A., and Ley, K. 2000. Blocking P-selectin protects from ischemia/reperfusioninduced acute renal failure. FASEB J. 14:48-54.

28. Linas, S.L., Shanley, P.F., Whittenburg, D., Berger, E., and Repine, J.E. 1988. Neutrophils accentuate ischemia-reperfusion injury in isolated perfused rat kidneys. Am. J. Physiol. 255:F728-F735.

29. Molitoris, B.A., Sandoval, R., and Sutton, T.A. 2002. Endothelial injury and dysfunction in ischemic acute renal failure. Crit. Care Med. 30(Suppl. 5):S235-S240.

30. Sutton, T.A., Fisher, C.J., and Molitoris, B.A. 2002. Microvascular endothelial injury and dysfunction during ischemic acute renal failure. Kidney Int. 62:1539-1549.

31. Badr, K.F., et al. 1989. Mesangial cell, glomerular and renal vascular responses to endothelin in the rat kidney. Elucidation of signal transduction pathways. J. Clin. Invest. 83:336-342.

32. Thadhani, R., Pascual, M., and Bonventre, J.V. 1996. Acute renal failure. N. Engl. J. Med. 334:1448-1460.

33. Racusen, L.C. 1998. Epithelial cell shedding in acute renal injury. Clin. Exp. Pharmacol. Physiol. 25:273-275.

34. Molitoris, B.A., Chan, L.K., Shapiro, J.I., Conger, J.D., and Falk, S.A. 1989. Loss of epithelial polarity: a novel hypothesis for reduced proximal tubule $\mathrm{Na}+$ transport following ischemic injury. J. Membr. Biol. 107:119-127.

35. Alejandro, V.S., et al. 1995. Postischemic injury, delayed function and $\mathrm{Na}+\mathrm{K}(+)$-ATPase distribution in the transplanted kidney. Kidney Int. 48:1308-1315

36. Edelstein, C., and Schrier, R. 1999. The role of calpain in renal proximal tubular and hepatocyte injury. In Calpain: pharmacology and toxicology of calcium-dependent protease. K.K. Wang and P.W. Yuen, editors. Taylor $\&$ Francis. Philadelphia, Pennsylvania, USA. 307-329.

37. Kribben, A., et al. 1994. Evidence for role of cytosolic free calcium in hypoxia-induced proximal tubule injury. J. Clin. Invest. 93:1922-1929.

38. Edelstein, C.L., et al. 1995. The role of cysteine proteases in hypoxia-induced rat renal proximal tubular injury. Proc. Natl. Acad. Sci. U. S. A. 92:7662-7666.

39. Edelstein, C.L., et al. 1997. Effect of glycine on prelethal and postlethal increases in calpain activity in rat renal proximal tubules. Kidney Int. 52:1271-1278.

40. Shi, Y., Melnikov, V.Y., Schrier, R.W., and Edelstein, C.L. 2000. Downregulation of the calpain inhibitor protein calpastatin by caspases during renal ischemia-reperfusion. Am. J. Physiol. Renal Physiol. 279:F509-F517.

41. Choi, K.H., Edelstein, C.L., Gengaro, P., Schrier, R.W., and Nemenoff, R.A. 1995. Hypoxia induces changes in phospholipase A2 in rat proximal tubules: evidence for multiple forms. Am. J. Physiol. 269:F846-F853.

42. Oliver, J., Mac, D.M., and Tracy, A. 1951. The pathogenesis of acute renal failure associated with traumatic and toxic injury: renal ischemia, nephrotoxic damage and the ischemic episode. J. Clin. Invest. 30:1307-1439.

43. Wangsiripaisan, A., Gengaro, P.E., Edelstein, C.L., and Schrier, R.W. 2001. Role of polymeric TammHorsfall protein in cast formation: oligosaccharide and tubular fluid ions. Kidney Int. 59:932-940.

44. Zuk, A., Bonventre, J.V., and Matlin, K.S. 2001. Expression of fibronectin splice variants in the postischemic rat kidney. Am. J. Physiol. Renal Physiol. 280:F1037-F1053.

45. Tanner, G.A. 1982. Nephron obstruction and tubuloglomerular feedback. Kidney Int. Suppl. 12:S213-S218.

46. Conger, J.D., Robinette, J.B., and Kelleher, S.P. 1984. Nephron heterogeneity in ischemic acute renal failure. Kidney Int. 26:422-429.

47. Noiri, E., et al. 1994. Cyclic RGD peptides ameliorate ischemic acute renal failure in rats. Kidney Int. 46:1050-1058

48. Goligorsky, M.S., and DiBona, G.F. 1993. Pathogenetic role of Arg-Gly-Asp-recognizing integrins in acute renal failure. Proc. Natl. Acad. Sci. U. S. A. 90:5700-5704.

49. Burke, T.J., Cronin, R.E., Duchin, K.L., Peterson, L.N., and Schrier, R.W. 1980. Ischemia and tubule obstruction during acute renal failure in dogs: mannitol in protection. Am. J. Physiol. 238:F305-F314.

50. Schnermann, J. 2003. Homer W. Smith Award lecture. The juxtaglomerular apparatus: from anatomical peculiarity to physiological relevance. J. Am. Soc. Nephrol. 14:1681-1694.

51. Molitoris, B.A., Falk, S.A., and Dahl, R.H. 1989. Ischemia-induced loss of epithelial polarity. Role of the tight junction. J. Clin. Invest. 84:1334-1339.

52. Edelstein, C., and Schrier, R. 2001. Pathophysiology of ischemic acute renal failure. In Diseases of the kidney and urinary tract. 7th edition. R.W. Schrier, editor. Lippincott Williams \& Wilkins. Philadelphia, Pennsylvania, USA. 1041-1070.

53. Myers, B.D., Chui, F., Hilberman, M., and Michaels, A.S. 1979. Transtubular leakage of glomerular filtrate in human acute renal failure. Am. J. Physiol. 237:F319-F325.

54. Yu, L., Gengaro, P.E., Niederberger, M., Burke, T.J., and Schrier, R.W. 1994. Nitric oxide: a mediator in rat tubular hypoxia/reoxygenation injury. Proc. Natl. Acad. Sci. U. S. A. 91:1691-1695.

55. Noiri, E., Peresleni, T., Miller, F., and Goligorsky, M.S. 1996. In vivo targeting of inducible NO synthase with oligodeoxynucleotides protects rat kidney against ischemia. J. Clin. Invest. 97:2377-2383.

56. Ling, H., et al. 1998. Effect of hypoxia on proximal tubules isolated from nitric oxide synthase knockout mice. Kidney Int. 53:1642-1646.

57. Ling, H., et al. 1999. Attenuation of renal ischemiareperfusion injury in inducible nitric oxide synthase knockout mice. Am. J. Physiol. 277:F383-F390.

58. Xia, Y., Dawson, V.L., Dawson, T.M., Snyder, S.H., and Zweier, J.L. 1996. Nitric oxide synthase generates superoxide and nitric oxide in arginine-depleted cells leading to peroxynitrite-mediated cellular injury. Proc. Natl. Acad. Sci. U. S. A. 93:6770-6774.

59. Noiri, E., et al. 2001. Oxidative and nitrosative stress in acute renal ischemia. Am. J. Physiol. Renal Physiol. 281:F948-F957.

60. Wangsiripaisan, A., et al. 1999. Effect of nitric oxide donors on renal tubular epithelial cell-matrix adhesion. Kidney Int. 55:2281-2288.

61. Chiao, H., et al. 1997. Alpha-melanocyte-stimulating hormone protects against renal injury after ischemia in mice and rats. J. Clin. Invest. 99:1165-1172.

62. Wang, W., et al. 2003. Interaction among nitric oxide, reactive oxygen species, and antioxidants during endotoxemia-related acute renal failure. Am. J. Physiol. Renal Physiol. 284:F532-F537.

63. Melnikov, V.Y., et al. 2001. Impaired IL-18 process- 
ing protects caspase-1-deficient mice from ischemic acute renal failure. J. Clin. Invest. 107:1145-1152.

64. Melnikov, V.Y., et al. 2002. Neutrophil-independent mechanisms of caspase-1- and IL-18-mediated ischemic acute tubular necrosis in mice. J. Clin. Invest. 110:1083-1091. doi:10.1172/JCI200215623.

65. Wang, W., et al. 2004. Endothelial nitric oxide synthase (eNOS) deficient mice exhibit increased susceptibility to endotoxin-induced acute renal failure. Am. J. Physiol. In press.

66. Atanasova, I., Burke, T.J., McMurtry, I.F., and Schrier, R.W. 1995. Nitric oxide synthase inhibition and acute renal ischemia: effect on systemic hemodynamics and mortality. Ren. Fail. 17:389-403.

67. Schwartz, D., et al. 1997. Inhibition of constitutive nitric oxide synthase (NOS) by nitric oxide generated by inducible NOS after lipopolysaccharide administration provokes renal dysfunction in rats. J. Clin. Invest. 100:439-448.

68. Sikorski, E.M., Hock, T., Hill-Kapturczak, N., and Agarwal, A. 2004. The story so far: molecular regulation of the heme oxygenase- 1 gene in renal injury. Am. J. Physiol. Renal Physiol. 286:F425-F441.

69. Arany, I., Megyesi, J.K., Kaneto, H., Tanaka, S., and Safirstein, R.L. 2004. Activation of ERK or inhibition of JNK ameliorates $\mathrm{H}_{2} \mathrm{O}_{2}$ cytotoxicity in mouse renal proximal tubule cells. Kidney Int. 65:1231-1239.

70. Park, K.M., Chen, A., and Bonventre, J.V. 2001. Prevention of kidney ischemia/reperfusion-induced functional injury and JNK, p38, and MAPK kinase activation by remote ischemic pretreatment. J. Biol. Chem. 276:11870-11876.

71. Price, P.M., Megyesi, J., and Safirstein, R.L. 2003. Cell cycle regulation: repair and regeneration in acute renal failure. Semin. Nephrol. 23:449-459.

72. Teehan, G.S., et al. 2003. Dialysis membrane and modality in acute renal failure: understanding discordant meta-analyses. Semin. Dial. 16:356-360.

73. Brivet, F.G., Kleinknecht, D.J., Loirat, P., and Landais, P.J. 1996. Acute renal failure in intensive care units: causes, outcome, and prognostic factors of hospital mortality; a prospective, multicenter study. French Study Group on Acute Renal Failure. Crit. Care Med. 24:192-198.

74. Poole, B., and Schrier, R. 2005. Acute renal failure in the intensive care unit. In Textbook of critical care. 5 th edition. F. Mitchell, E. Abraham, J.Vincent, and P. Kochanek, editors. Elsevier. Philadelphia, Pennsylvania, USA. In press.

75. Nakamoto, M., Shapiro, J.I., Shanley, P.F., Chan, L., and Schrier, R.W. 1987. In vitro and in vivo protective effect of atriopeptin III on ischemic acute renal failure. J. Clin. Invest. 80:698-705.

76. Allgren, R.L., et al. 1997. Anaritide in acute tubular necrosis. Auriculin Anaritide Acute Renal Failure Study Group. N. Engl. J. Med. 336:828-834.

77. Schrier, R., and Wang, W. 2004. Acute renal failure and sepsis. N. Engl. J. Med. 351:35-45.

78. Wang, W., et al. 2002. Protective effect of renal denervation on normotensive endotoxemiainduced acute renal failure in mice. Am. J. Physiol. Renal Physiol. 283:F583-F587.

79. Burke, T.J., Arnold, P.E., and Schrier, R.W. 1983. Prevention of ischemic acute renal failure with impermeant solutes. Am. J. Physiol. 244:F646-F649.

80. Conger, J.D., Falk, S.A., Yuan, B.H., and Schrier, R.W. 1989. Atrial natriuretic peptide and dopamine in a rat model of ischemic acute renal failure. Kidney Int. 35:1126-1132.

81. Lieberthal, W., Sheridan, A.M., and Valeri, C.R. 1990. Protective effect of atrial natriuretic factor and mannitol following renal ischemia. Am. J. Physiol. 258:F1266-F1272.

82. Knotek, M., et al. 2001. Endotoxemic renal failure in mice: role of tumor necrosis factor independent of inducible nitric oxide synthase. Kidney Int. 59:2243-2249.

83. Abraham, E., et al. 1998. Double-blind randomised controlled trial of monoclonal antibody to human tumour necrosis factor in treatment of septic shock. NORASEPT II Study Group. Lancet. 351:929-933.
84. Siegel, N.J., et al. 1980. Enhanced recovery from acute renal failure by the postischemic infusion of adenine nucleotides and magnesium chloride in rats. Kidney Int. 17:338-349.

85. Kelly, K.J., Plotkin, Z., and Dagher, P.C. 2001. Guanosine supplementation reduces apoptosis and protects renal function in the setting of ischemic injury. J. Clin. Invest. 108:1291-1298. doi:10.1172/ JCI200113018.

86. Meldrum, K.K., Meldrum, D.R., Sezen, S.F., Crone, J.K., and Burnett, A.L. 2001. Heat shock prevents simulated ischemia-induced apoptosis in renal tubular cells via a PKC-dependent mechanism. Am.J. Physiol. Regul. Integr. Comp. Physiol. 281:R359-R364.

87. Tepel, M., et al. 2000. Prevention of radiographiccontrast-agent-induced reductions in renal function by acetylcysteine. N. Engl. J. Med. 343:180-184.

88. Hirschberg, R., et al. 1999. Multicenter clinical trial of recombinant human insulin-like growth factor I in patients with acute renal failure. Kidney Int. 55:2423-2432.

89. Brodsky, S.V., et al. 2002. Endothelial dysfunction in ischemic acute renal failure: rescue by transplanted endothelial cells. Am. J. Physiol. Renal Physiol. 282:F1140-F1149.

90. Kale, S., et al. 2003. Bone marrow stem cells contribute to repair of the ischemically injured renal tubule. J. Clin. Invest. 112:42-49. doi:10.1172/JCI200317856.

91. Lin, F., et al. 2003. Hematopoietic stem cells contribute to the regeneration of renal tubules after renal ischemia-reperfusion injury in mice. J. Am. Soc. Nephrol. 14:1188-1199.

92. Gupta, S., Verfaillie, C., Chmielewski, D., Kim, Y., and Rosenberg, M.E. 2002. A role for extrarenal cells in the regeneration following acute renal failure. Kidney Int. 62:1285-1290.

93. Safirstein, R., DiMari, J., Megyesi, J., and Price, P. 1998. Mechanisms of renal repair and survival following acute injury. Semin. Nephrol. 18:519-522.

94. Thadhani, R., Pascual, M., and Bonventre, J. 1996. Acute renal failure. N. Engl. J. Med. 334:1448-1460. 